УДК $630 * 181.324$

\title{
ДИНАМИКА ЖИРНОКИСЛОТНОГО СОСТАВА И АКТИВНОСТИ АЦИЛ-ЛИПИДНЫХ ДЕСАТУРАЗ В ХВОЕ PINUS SYLVESTRIS L., ПРОИЗРАСТАЮЩЕЙ В ИРКУТСКОЙ ОБЛАСТИ
}

\author{
() И.М. Романова, М.А. Живетьев", Л.В. Дударева, И.А. Граскова \\ Сибирский институт фризиологии и биохимии растений, ул. Лермонтова, \\ 132, Иркутск, 664033 (Россия), e-mail: nik.19@mail.ru
}

Температура является одним из существенных экологических факторов окружающей среды, который характеризуется очень высокой изменчивостью. В первую очередь действию температурного фактора подвергаются клеточные мембраны, устойчивость которых связана как с наличием полиненасыщенных жирных кислот в структуре мембран, так и с активностью ацил-липидных десатураз, отвечающих за текучесть мембран.

Исследовано изменение жирнокислотного состава хвои Pinus sylvestris L. в течение вегетационного периода. Показана динамика насыщенных и ненасыщенных жирных кислот и роль ацил-липидных десатураз в адаптивных изменениях жирнокислотного состава.

В хвое сосны обыкновенной, произрастающей в окрестностях Мельничной Пади, обнаружено 27 жирных кислот, содержание которых изменяется в зависимости от сезона года.

В общем содержании жирных кислот преобладают ненасыщенные жирные кислоты, максимальное содержание которых наблюдается в период низких отрицательных температур, насыщенных жирных кислот - в весенний период.

Самые высокие значения индекса двойных связей $(1,84-1,88)$ наблюдаются в зимний период в связи с низким содержанием насыщенных жирных кислот, самые низкие значения индекса - в летний период.

Изменение сезонной активности ацил-липидных $\omega-3, \omega-6$ и $\omega$-9-десатураз можно проследить по содержанию основных кислот $\mathrm{C}_{18}$ ряда: олеиновой, линолевой и $\alpha$-линоленовой.

Ключевые слова: Pinus sylvestris, жирные кислоты, десатуразы.

\section{Введение}

Известно, что для нормального функционирования мембрана клеток должна находиться в жидком фазовом состоянии. В ходе эволюции у растений выработались механизмы, регулирующие жидкое состояние мембран посредством изменения жирнокислотного состава мембранных липидов $[1,2]$.

Следствием действия неблагоприятного фактора является изменение текучести мембраны, которое достигается десатурацией жирных кислот мембранных липидов. Первоочередную роль в данном процессе играют десатуразы - ферменты, катализирующие превращение одинарной связи между атомами углерода в ацильных цепях $(\mathrm{C}-\mathrm{C})$ в двойные связи $(\mathrm{C}=\mathrm{C})[2,3]$.

Учитывая тот факт, что основной лесообразующей породой на территории Иркутской области является сосна обыкновенная, актуально изучение механизмов ее адаптации к условиям окружающей среды в разные периоды онтогенеза. Сосна обыкновенная является удобным объектом для изучения адаптации растений к сезонным изменениям в течение нескольких лет.

\footnotetext{
Романова Ирина Михайловна - ведущий инженер, e-mail: nik.19@mail.ru

Живетьев Максим Аркадьевич - кандидат биологических наук, научный сотрудник, e-mail: nik.19@mail.ru

Дударева Любовь Виссарионовна - кандидат биологических наук, заведующая лабораторией физикохимических методов анализа, e-mail: laser@sifibr.irk.ru Граскова Ирина Алексеевна - доктор биологических наук, ведущий научный сотрудник, e-mail: graskova@sifibr.irk.ru
}

\section{Экспериментальная часть}

Объектом исследований являлась хвоя первого, второго и третьего годов сосны обыкновенной, взятая из средней части кроны. Пробы хвои отбирались ежемесячно в течение 2011-2012 гг. в окрестностях пос. Мельничная Падь, Иркутская область.

Для определения жирнокислотного состава липидов использовался модифицированный метод

\footnotetext{
* Автор, с которым следует вести переписку.
} 
[4]. Образцы для жирнокислотного анализа (1-2 г) фиксировали и растирали в жидком азоте до получения гомогенной массы для экстракции липидов. Экстракцию липидов из тканей исследуемых объектов проводили с использованием системы растворителей хлороформ - метанол - вода (1: $2: 0,8$ v/v/v). Для удаления хлороформа из экстракта липидов использовали роторный испаритель RVO-64 (Чехия). Для получения метиловых эфиров жирных кислот к экстракту липидов после удаления растворителя добавляли $1 \%$ метанольный раствор $\mathrm{H}_{2} \mathrm{SO}_{4}$ и нагревали на водяной бане при $60{ }^{\circ} \mathrm{C}$ в течение 30 мин. После охлаждения метиловые эфиры жирных кислот трижды экстрагировали гексаном. Анализ полученных метиловых эфиров жирных кислот проводили методом газожидкостной хроматографии с использованием хромато-масс-спектрометра 5973N/6890N MSD/DS Agilent Technology. Капиллярная колонка HP-INNOWAX (30 мм × 250 мм ×0,50 мкм), градиент температуры: от 100 до $150{ }^{\circ} \mathrm{C}$ со скоростью $10^{\circ} \mathrm{C}$ в мин; от 150 до $255^{\circ} \mathrm{C}$ со скоростью $3{ }^{\circ} \mathrm{C}$ в мин. Для расчета эквивалентной длины цепи использовали изократический режим, температура колонки $-200{ }^{\circ} \mathrm{C}$. Газ-носитель - гелий, скорость потока газа - 1 мл/мин. Масс-спектрометр - квадруполь, способ ионизации электронный удар (ЕI) (энергия ионизации: 70 эВ). Для идентификации метиловых эфиров жирных кислот липидов использовали значения индекса удерживания $R_{\mathrm{f}}$ (для стандартных насыщенных и ненасыщенных ЖК) и индекса ECL (эквивалентной длины цепи), а также библиотеку масс-спектров NIST05. Относительное содержание ЖК определяли в весовых процентах от общего их содержания в исследуемом образце.

Активность ацил-липидных мембранных $\omega 9, \omega 6$ и $\omega 3$ десатураз, катализирующих введение двойных связей в углеродные цепи олеиновой $\left(\mathrm{C}_{18: 1}\right)$, линолевой $\left(\mathrm{C}_{18: 2}\right)$ и $\alpha$-линоленовой $\left(\mathrm{C}_{18: 3}\right)$ кислот, определялась соответственно как стеароил- (SDR), олеил- (ODR) и линолеил- (LDR) десатуразные отношения, рассчитанные на основании содержания (процентного от суммы ЖК) компонентов типа $\mathrm{C}_{18}$, как это описано в работах [5-9], по формулам:

$$
\begin{gathered}
\mathrm{SDR}=\left(\% \mathrm{C}_{18: 1}\right) /\left(\% \mathrm{C}_{18: 0}+\% \mathrm{C}_{18: 1}\right) \\
\mathrm{ODR}=\left(\% \mathrm{C}_{18: 2}+\% \mathrm{C}_{18: 3}\right) /\left(\% \mathrm{C}_{18: 1}+\% \mathrm{C}_{18: 2}+\% \mathrm{C}_{18: 3}\right) \\
\mathrm{LDR}=\left(\% \mathrm{C}_{18: 3}\right) /\left(\% \mathrm{C}_{18: 2}+\% \mathrm{C}_{18: 3}\right)
\end{gathered}
$$

где $\mathrm{C}_{18: 0}, \mathrm{C}_{18: 1}, \mathrm{C}_{18: 2}, \mathrm{C}_{18: 3}$ - процентное содержание от суммы кислот стеариновой, олеиновой, линолевой и линоленовой кислот соответственно.

Для оценки ненасыщенности ЖК в тканях листьев использовали индекс двойных связей (ИДС):

$$
\text { ИДС }=\sum P_{\mathrm{j}} n_{\mathrm{j}} / 100
$$

где $P_{\mathrm{j}}$ - содержание ЖК (вес. \%); $n_{\mathrm{j}}$ - количество двойных связей в каждой кислоте. Также использовали коэффициент ненасыщенности жирных кислот $(K)$ как отношение суммы ненасыщенных ЖК к сумме насыщенных.

Сумму насыщенных жирных (НЖК) и ненасыщенных (ННЖК) кислот определяли путем суммирования процентного содержания насыщенных и ненасыщенных жирных кислот соответственно.

\section{Обсуждение результатов}

Жирнокислотный состав хвои сосны обыкновенной, произрастающей в Мельничной Пади, в период исследования включал 27 жирных кислот, отличающихся по числу углеродных цепей и двойных связей. Длина углеродных цепей варьировала от 12 до 22 атомов. Основными жирными кислотами в период исследования были пальмитиновая $\left(\mathrm{C}_{16: 0}\right)$, линолевая $\left(\mathrm{C}_{18: 2(\mathrm{n}-6)}\right)$ и $\alpha$-линоленовая $\left(\mathrm{C}_{18: 3(\mathrm{n}-3)}\right)$. Также высокое содержание отмечается для олеиновой $\left(\mathrm{C}_{18: 1(\mathrm{n}-9)}\right)$, пиноленовой $\left(\mathrm{C}_{18: 3(5,9,12)}\right)$, скиадоновой $\left(\mathrm{C}_{20: 3(5,11,14)}\right)$ кислот. Высокое содержание этих кислот может быть связано с тем, что они принимают активное участие в образовании клеточных мембран [10].

Содержание пальмитиновой кислоты в осенний период составляет 17-24\%, в то время как в остальное время года колеблется от 14 до $17 \%$.

В весенний период, период активации всех физиологических процессов, содержание олеиновой кислоты резко увеличивается (от 7,09 до 14,52\% в хвое первого года, от 8,36 до 18,49\% - второго года, от 10,40 до 13,93\% - хвое третьего года). В этот же период наблюдается снижение содержания пальмитиновой кислоты на $1-3 \%$. 
Жирнокислотный состав хвои разного возраста (1, 2, 3 года) Pinus sylvestris L., произрастающей в Мельничной Пади, \% от общего содержания

\begin{tabular}{|c|c|c|c|c|c|c|c|c|c|c|c|c|}
\hline Сезон года & \multicolumn{3}{|c|}{ Осень (IX-XI) } & \multicolumn{3}{|c|}{ Зима (XII, I, II) } & \multicolumn{3}{|c|}{ Весна (III-V) } & \multicolumn{3}{|c|}{ Лето (VI-VIII) } \\
\hline Возраст хвои, лет & 1 & 2 & 3 & 1 & 2 & 3 & 1 & 2 & 3 & 1 & 2 & 3 \\
\hline $\mathrm{C}_{12: 0}$ & - & - & - & - & - & 2,28 & 2,89 & - & 2,12 & 1,17 & - & 2,57 \\
\hline $\mathrm{C}_{14: 0}$ & 1,40 & 3,34 & 3,99 & 3,99 & 2,72 & 3,00 & 2,23 & 2,54 & 2,95 & 3,54 & 2,59 & 6,08 \\
\hline $\mathrm{C}_{15: 0}$ & - & - & - & - & 0,16 & - & - & - & 0,37 & - & - & 0,47 \\
\hline $\mathrm{C}_{16: 0}$ & 20,42 & 24,22 & 17,67 & 17,67 & 15,28 & 15,40 & 17,44 & 12,24 & 14,13 & 16,69 & 17,63 & 13,27 \\
\hline $\mathrm{C}_{16: 1(\mathrm{n}-5)}$ & 0,40 & 0,51 & - & 0,00 & 0,39 & 0,36 & 0,49 & 0,31 & 0,24 & 0,97 & 1,31 & 0,78 \\
\hline $\mathrm{C}_{16: 1(\mathrm{n}-7)}$ & - & - & - & - & 0,26 & 0,60 & 0,32 & 0,30 & 0,25 & - & - & 0,21 \\
\hline $\mathrm{C}_{16: 1(\mathrm{n}-9)}$ & 0,10 & - & - & - & - & - & 0,40 & 0,34 & 0,44 & - & - & 0,51 \\
\hline $\mathrm{C}_{16: 2(\mathrm{n}-6)}$ & 0,19 & - & - & - & 0,31 & - & 0,27 & - & 0,08 & - & - & 0,16 \\
\hline $\mathrm{C}_{17: 0 \text {-a }}$ & 0,51 & 0,69 & - & - & 1,04 & 1,00 & 0,75 & 0,90 & 1,16 & 1,11 & - & 0,94 \\
\hline $\mathrm{C}_{17: 0}$ & 0,19 & 0,43 & - & - & 0,39 & 0,35 & 0,37 & 0,36 & 0,43 & 0,45 & 0,82 & 0,86 \\
\hline $\mathrm{C}_{16: 3(\mathrm{n}-3)}$ & 0,67 & 0,52 & 1,57 & 1,57 & 1,12 & 1,09 & 0,78 & 0,83 & 0,78 & 1,20 & - & 1,50 \\
\hline $\mathrm{C}_{18: 0}$ & 1,05 & 3,34 & 1,94 & 1,94 & 2,56 & 1,56 & 2,43 & 1,99 & 1,75 & 3,24 & 4,67 & 8,52 \\
\hline $\mathrm{C}_{18: 1(\mathrm{n}-9)}$ & 6,62 & 10,45 & 7,09 & 7,09 & 8,36 & 10,40 & 14,52 & 18,49 & 13,93 & 7,79 & 7,36 & 8,10 \\
\hline $\mathrm{C}_{18: 1(\mathrm{n}-7)}$ & - & - & 1,09 & 1,09 & 0,99 & 0,74 & 0,55 & 0,77 & 0,63 & 0,44 & 0,68 & 0,82 \\
\hline $\mathrm{C}_{18: 2(\mathrm{n}-6)}$ & 19,99 & 18,74 & 18,70 & 18,70 & 20,72 & 20,35 & 24,88 & 21,94 & 22,37 & 19,36 & 20,64 & 18,54 \\
\hline $\mathrm{C}_{18: 2(5,9)}$ & 0,24 & - & - & - & 0,29 & - & 0,29 & 0,33 & 0,42 & 0,47 & - & 0,44 \\
\hline $\mathrm{C}_{18: 3(5,9,12)}$ & 6,59 & 7,39 & 8,42 & 8,42 & 8,24 & 9,01 & 5,78 & 8,33 & 8,14 & 6,78 & 7,62 & 7,05 \\
\hline $\mathrm{C}_{18: 3(\mathrm{n}-3)}$ & 29,42 & 20,41 & 21,10 & 21,10 & 22,71 & 19,33 & 16,56 & 16,15 & 15,80 & 25,30 & 29,14 & 21,03 \\
\hline $\mathrm{C}_{18: 4(5,9,12,15)}$ & 1,46 & 2,12 & 2,78 & 2,78 & 3,13 & 3,79 & 1,93 & 2,63 & 2,74 & 2,31 & 2,97 & 2,57 \\
\hline $\mathrm{C}_{20: 0}$ & 0,40 & 1,15 & 2,37 & 2,37 & 1,11 & 1,37 & 1,13 & 1,01 & 1,14 & 1,34 & 1,37 & 1,31 \\
\hline $\mathrm{C}_{20: 1(\mathrm{n}-9)}$ & - & - & - & - & 0,24 & 0,31 & 0,50 & 0,40 & 0,39 & 0,28 & 0,29 & 0,36 \\
\hline $\mathrm{C}_{20: 2(\mathrm{n}-9)}$ & 1,88 & 1,32 & 1,70 & 1,70 & 1,37 & 1,28 & 1,28 & 1,50 & 1,55 & 0,87 & 0,98 & 0,74 \\
\hline $\mathrm{C}_{20: 3(5,11,14)}$ & 5,70 & 4,54 & 6,88 & 6,88 & 5,40 & 6,47 & 4,42 & 5,90 & 5,75 & 6,50 & 5,82 & 6,11 \\
\hline $\mathrm{C}_{20: 3(7,11,14)}$ & 0,46 & 0,35 & 1,25 & 1,25 & 1,34 & 1,20 & 1,20 & 1,23 & 1,37 & 1,20 & 0,93 & 1,08 \\
\hline $\mathrm{C}_{20: 3(11,14,17)}$ & - & - & - & - & 0,44 & 0,26 & 0,41 & 0,38 & 0,37 & 0,32 & - & 0,23 \\
\hline $\mathrm{C}_{20: 4(5,11,14,17)}$ & 0,38 & 0,38 & 1,03 & 1,03 & 1,02 & 1,07 & 0,63 & 0,80 & 0,79 & 1,04 & 1,11 & 0,77 \\
\hline $\mathrm{C}_{22: 0}$ & 1,94 & 2,10 & 2,43 & 2,43 & 2,26 & 2,27 & 1,37 & 2,07 & 1,93 & 2,77 & 2,31 & 1,71 \\
\hline
\end{tabular}

Динамика $\alpha$-линоленовой кислоты схожа с динамикой пальмитиновой кислоты. В весенний период происходит резкое снижение содержания этой кислоты на 4-5\% от общего содержания кислот у хвои каждого возраста. К летнему периоду происходит обратный процесс: содержание $\alpha$-линоленовой кислоты резко увеличивается на 6-10\%.

Обратная динамика наблюдается в содержании линолевой кислоты: в весенний период резко увеличивается с 20 до 24\% и так же резко понижается к летнему периоду.

$\mathrm{B}$ целом динамика кислот $\mathrm{C}_{18}$ ряда в течение всего вегетационного периода схожа.

Анализ содержания ненасыщенных жирных кислот в течение вегетационного периода показал, что в общем составе преобладают ненасыщенные жирные кислоты (рис. 1). Максимальное содержание ННЖК наблюдается в зимний период, что обусловлено изменением жирнокислотного состава для поддержания жидкого фазового состояния мембраны. К весеннему периоду содержание ННЖК снижается, это ведет к повышению относительного содержания НЖК, что, возможно, свидетельствует о перестройке клеточного метаболизма к более благоприятным температурным условиям.

Соотношение ненасыщенных и насыщенных жирных кислот наглядно иллюстрирует коэффициент ненасыщенности жирных кислот (рис. 1), но более информативным показателем, учитывающим еще и количество двойных связей в молекулах ненасыщенных жирных кислот, является ИДС (индекс двойных связей).

В динамике индекса двойных связей (рис. 2) наблюдается следующее: самые высокие значения $(1,84-1,88)$ отмечаются в зимний период, что связано с низким содержанием насыщенных жирных кислот. В период активного роста хвои и начала подготовки к размножению общее содержание ненасыщенных жирных кислот уменьшается в основном за счет уменьшения содержания $\alpha$-линоленовой и пиноленовой кислот (снижение на 4-5\%), что приводит к снижению значения ИДС $(1,60-1,70)$. Самые низкие значения ИДС наблюдаются в летний период, когда содержание насыщенных кислот повышается, что обусловлено 
высокими температурными показателями в данный период. Отличается только ИДС у хвои первого года его значение достигает 1,83 (в хвое второго года $-1,49$, третьего - 1,69). При снижении физиологической активности и подготовке организма к сезонному понижению температуры в зимний период значения ИДС увеличиваются за счет увеличения содержания ненасыщенных кислот, участвующих в увеличении текучести мембранных липидов и, следовательно, в адаптации клетки к низким температурам.

Изменение степени ненасыщенности жирных кислот происходит за счет участия ферментов. Исследовано изменение сезонной активности $\omega-3, \omega-6$ и $\omega$-9-десатураз, которые осуществляют реакцию десатурации жирных кислот в положении 3, 6 и 9 соответственно. Об их активности можно судить по коэффициентам стеароил-десатуразного (SDR), олеоил-десатуразного (ODR) и линолеил-десатуразного (LDR) отношений (рис. 3).

Значения SDR находятся в пределах 0,72-0,94 (кроме хвои второго года - значение SDR составляет $0,61)$, при этом минимальные значения наблюдаются в основном в летний период. Высокие показатели стеароил-десатуразного отношения можно объяснить тем, что синтез олеиновой кислоты не зависит от каких-либо факторов и происходит в течение всего вегетационного периода. Более высокие стабильные значения в весенний период $(0,85-0,91)$ связаны с резким увеличением олеиновой кислоты и синтезом линолевой кислоты в период активного роста хвои.

Значения ODR находятся в более низких значениях, чем SDR $(0,71-0,89)$. Самые низкие значения наблюдаются в весенний период, в то время, когда отмечаются самые высокие показатели олеиновой и линолевой кислот. Самые высокие значения наблюдаются осенью и поздним летом, когда происходит усиленный синтез альфа-линоленовой кислоты (период заморозков, переход к покою).

Значения линолеил-десатуразного отношения в период исследования находились в пределах 0,47-0,64. Как и значения стеароил-десатуразного отношения, самые высокие значения LDR наблюдаются осенью и поздним летом, в периоды, когда содержание альфа-линоленовой кислоты находится в пределах 20-29\%. Низкие значения в весенний период могут быть обусловлены прекращением синтеза линоленовой кислоты.

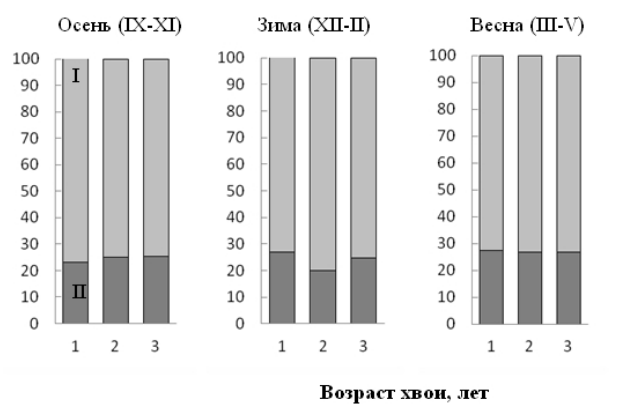

Рис. 1. Содержание ненасыщенных (I) и насыщенных (II) жирных кислот в хвое разного возраста Pinus sylvestris L., произрастающей в Мельничной Пади, \% от общего содержания
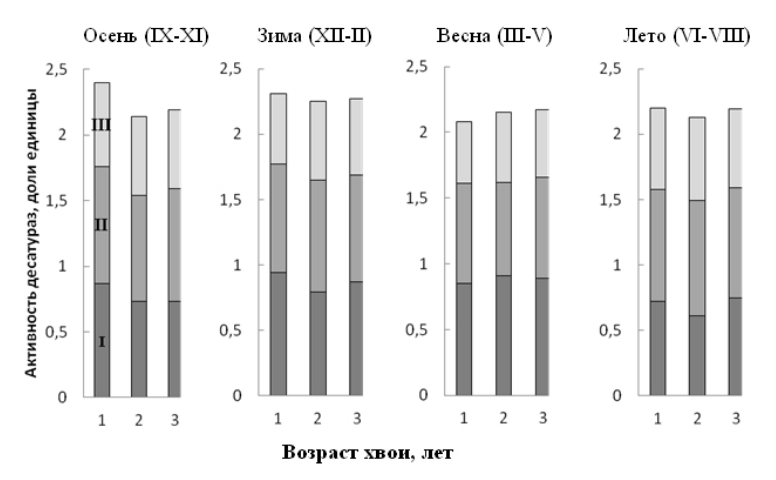
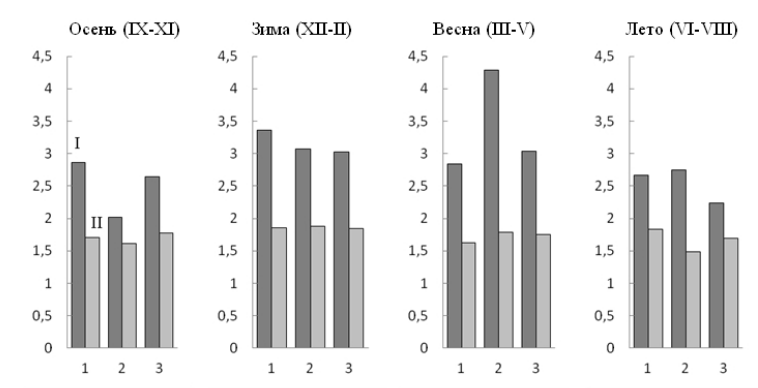

Возраст хвон, лет

Рис. 2. Коэффициенты ненасыщенности жирных кислот К (I) и индексы двойных связей ИДС (II) в хвое разного возраста Pinus sylvestris L., произрастающей в Мельничной Пади, доли единицы

Рис. 3. Стеароил-десатуразное (SDR) (I), олеоилдесатуразное (ODR) (II) и линолеил-десатуразное (LDR) (III) отношения в хвое разного возраста Pinus sylvestris L., произрастающей в Мельничной Пади 


\section{Bbыводbl}

Жирнокислотный состав хвои сосны обыкновенной изменяется в зависимости от сезона года, что, по всей видимости, связано с температурным фактором.

Максимальное содержание ненасыщенных жирных кислот наблюдалось в период низких отрицательных температур. Эту же динамику повторяет индекс двойных связей.

Значения SDR находились в пределах 0,72-0,94, причем минимальные значения наблюдались в летний период, высокие $(0,85-0,91)$ - в весенний, при резком увеличении содержания олеиновой и синтезе линолевой кислот в период активного роста хвои.

Значения ODR в течение года находились в пределах 0,71-0,89, низкие значения отмечаются в весенний период, когда наиболее высокие показатели олеиновой и линолевой кислот. Высокие значения ODR наблюдаются осенью и поздним летом, когда происходит усиленный синтез $\alpha$-линоленовой кислоты.

Значения LDR находились в пределах 0,47-0,64 и были наиболее высоки осенью и поздним летом, когда содержание $\alpha$-линоленовой кислоты находилось в пределах 20-29\%.

\section{Список литературы}

1. Алаудинова Е.В., Миронов П.В., Репях С.М. Жирные кислоты мембранных липидов живых тканей почек лиственницы сибирской // Химия растительного сырья. 2000. №2. С. 41-45.

2. Лось Д.А. Молекулярные механизмы холодоустойчивости растений // Вестник Российской академии наук. 2005. №4. С. 338-345.

3. Лось Д.А. Структура, регуляция экспрессии и функционирование десатураз жирных кислот // Успехи биологической химии. 2001. Т. 41. С. 163-198.

4. Christie W.W. Preparation of lipid extracts from tissues // Advances in Lipid Methodology. Dundee, Scotland. 1993. Vol. 2. Pp. 195-213.

5. Jaworski J.G., Stumpf P.K. Fat metabolism in higher plants. Properties of a soluble stearyl-acyl carrier protein desaturase from maturing Carthamus tinctorius // Arch. Biochem. Biophys. 1974. Vol. 162 (1). Pp. 158-165.

6. Mazliak P. Desaturation Processes in Fatty Acid and Acyl Lipid Biosynthesis // J. Plant Physiol. 1994. Vol. 143. Pp. 399-406.

7. Cartea M.E., Migdal M., Galle A.M., Pelletier G., Guerche P. Comparison of Sense and Antisense Methodologies for Modifying the Fatty Acid Composition of Arabidopsis thaliana oilseed // Plant Sci. 1998. Vol. 136 (2). Pp. 181-194.

8. Алаудинова Е.В., Миронов П.В. Липиды меристем лесообразующих хвойных пород Центральной Сибири в условиях низкотемпературной адаптации. 2. Особенности метаболизма жирных кислот фосфолипидов меристем Larix Sibirica Ledeb., Picea Obovata L. и Pinus Sylvestris L. // Химия растительного сырья. 2009. №2. C. 71-76.

9. Живетьев М.А., Граскова И.А., Дударева Л.В. Столбикова А.В., Соколова Н.А., Войников В.К. Динамика сезонных изменений жирнокислотного состава, степени ненасыщенности жирных кислот и активности ациллипидных десатураз в тканях некоторых лекарственных растений, произрастающих в условиях Предбайкалья // Химия растительного сырья. 2011. №4. С. 223-230.

10. Кириченко К.А., Побежимова Т.П., Соколова Н.А., Столбикова А.В., Дударева Л.В., Войников В.К. Жирнокислотный состав общих липидов высших водных растений из реки Ангары // Химия растительного сырья. 2011. №2. С. 97-102. 
Romanova I.M., Zhivetev M.A.*, Dudareva L.V., Graskova I.A. VARIATION OF FATTY ACID COMPOSITION AND ACTIVITY OF ACYL-LIPID DESATURASES OF PINUS SYLVESTRIS L. NEEDLES, GROWING IN THE IRKUTSK REGION

Siberian Institute of Plant Physiology and Biochemistry, Siberian Branch of the Russian Academy of Sciences,

ul.Lermontova, 132, Irkutsk,664033 (Russia),e-mail:nik19@mail.ru

Temperature - a significant ecological factor of the environment, which is characterized by very high variation. First of all, the cell membranes are subjected to the temperature factor, whose resistance associated with the presence of polyunsaturated fatty acids in the membrane structure and the activity of acyl-lipid desaturases responsible for membrane fluidity.

The change in the fatty acid composition on needles of during vegetation period was investigated. The dynamics of saturated and unsaturated fatty acids and the role of acyl-lipid desaturases in adaptive changes in fatty acid composition are shows.

27 fatty acids are found in the needles of Pinus sylvestris L. growing in the vicinity of the Melnichnaya Pad, which content are varies depending on the season.

The fatty acid composition of Pinus sylvestris L. needles were studied during the year. The dynamics of saturated and unsaturated fatty acids and the role of acyl-lipid desaturases to adaptive changes in fatty acid composition were shows.

The unsaturated fatty acids are predominate in general content of fatty acids, the maximum content of which is observed during the period of low freezing temperatures, saturated fatty acids-in the spring period.

Whereas the highest values of the of double bonds index $(1,84-1,88)$ are observed in winter due to the low content of saturated fatty acids, the lowest value of the index observed in the summer.

Also there was relationship between content of oleic, linoleic and $\alpha$-linolenic acids with modification activity of acyllipid $\omega-3, \omega-6$ and $\omega-9$ desaturases.

Keywords: Pinus sylvestris L., fatty acid, acyl-lipid desaturases.

\section{Reference}

1. Alaudinova E.V., Mironov P.V., Repiakh S.M. Khimiia rastitel'nogo syr'ia, 2000, no. 2, pp. 41-45. (in Russ.).

2. Los' D.A. Vestnik Rossiiskoi Akademii Nauk, 2005, no. 4, pp. 338-345. (in Russ.).

3. Los' D.A. Uspekhi biolo-gicheskoi khimii, 2001, vol. 41, pp. 163-198. (in Russ.).

4. Christie W.W. Advances in Lipid Methodology. Dundee, Scotland, 1993, vol. 2, pp. 195-213.

5. Jaworski J.G., Stumpf P.K. Arch. Biochem. Biophys. 1974, vol. 162 (1), pp. 158-165.

6. Mazliak P. J. Plant Physiol. 1994, vol. 143, pp. 399-406.

7. Cartea M.E., Migdal M., Galle A.M., Pelletier G., Guerche P. Plant Sci., 1998, vol. 136 (2), pp. 181-194.

8. Alaudinova E.V., Mironov P.V. Khimiia rastitel'nogo syr'ia, 2009, no. 2, pp. 71-76. (in Russ.).

9. Zhivet'ev M.A., Graskova I.A., Dudareva L.V. Stolbikova A.V., Sokolova N.A., Voinikov V.K. Khimiia rastitel'nogo syr'ia, 2011, no. 4, pp. 223-230. (in Russ.).

10. Kirichenko K.A., Pobezhimova T.P., Sokolova N.A., Stolbikova A.V., Dudareva L.V., Voinikov V.K. Khimiia rastitel'nogo syr'ia, 2011, no. 2, pp. 97-102. (in Russ.).

Received May 7, 2015

Revised March 14, 2016

\footnotetext{
* Corresponding author.
} 